\title{
Perioperative management of a patient presenting with a spontaneously ruptured esophagus
}

\author{
[La prise en charge périopératoire d'un patient qui présente une rupture \\ asophagienne spontanée]
}

Chandra Kant Pandey MD, Neeta Bose MD, Nihar Ranjan Dash MS, Namita Singh MD PDCC, Rajan Saxena MS MCH

Purpose: To report a case of spontaneous rupture of the esophagus and its anesthetic management.

Clinical features: A 52-yr-old male presented with a seven day history of chest pain, respiratory distress, and swelling in the neck following forceful vomiting. Examination revealed hypotension, decreased air entry in the right lower lung field with crepitations, epigastric tenderness with abdominal distension and guarding of both right and left hypochondria. A contrast esophagogram showed extravasation of contrast material from the lower third of the esophagus into the mediastinum without pleural cavity involvement. Reinforced primary closure of a $5-\mathrm{cm}$ transmural tear in the right anterolateral wall of the esophagus $5 \mathrm{~cm}$ above the gastroesophageal junction was performed along with right-sided chest drainage.

The anesthetic drugs and technique in this case were selected to avoid any increase in intra-abdominal pressure to prevent further spillage of gastric contents into the mediastinum through the perforation. Invasive monitoring was used to assess early hemodynamic changes and to administer fluid therapy and vasoactive drugs. Due to prolonged surgery, lung congestion, large fluid shifts, a long surgical incision and abnormal arterial blood gases, the patient was ventilated mechanically in the intensive care unit. Subsequently he developed an esophageal leak, septic shock, and multiple organ failure and died.

Conclusion: In a patient with a spontaneous rupture of esophagus, the anesthetic considerations include avoidance of further aggravation of the esophageal tear, and resuscitation from a morbid inflammatory condition.
Objectif: Décrire un cas de rupture spontanée de l'œsophage et son traitement anesthésique.

Éléments cliniques: Un homme de 52 ans avait des douleurs thoraciques depuis sept jours, souffrait de détresse respiratoire et présentait de l'enflure au cou faisant suite à des vomissements violents. L'examen a révélé de l'hypotension, une diminution du murmure vésiculaire au niveau de la plage pulmonaire inférieure droite et des crépitations, une sensibilité épigastrique accompagnée de ballonnement abdominal et une défense musculaire des hypocondres droit et gauche. Un œsophagogramme de contraste a montré l'extravasation du matériel de contraste au niveau du tiers inférieur de l'œsophage migrant vers le médiastin sans extravasation vers la cavité pleurale. Une suture primaire renforcée d'une déchirure transmurale de $5 \mathrm{~cm}$ à la paroi antéro-latérale droite de l'œsophage, $5 \mathrm{~cm}$ au-dessus de la jonction gastro-œesophagienne, et un drainage thoracique du côté droit ont été réalisés.

Le choix des médicaments et de la technique anesthésiques visait à éviter toute augmentation de pression intra-abdominale qui aurait pu provoquer d'autre fuite du contenu gastrique vers le médiastin au travers de la perforation. Un monitorage effractif a permis d'évaluer les changements hémodynamiques précoces et d'administrer une thérapie liquide et des médicaments vasoactifs. Étant donné la longueur de l'opération, la congestion pulmonaire, la mobilisation d'importants volumes de liquides, une longue incision chirurgicale et des gaz artériels anormaux, la ventilation mécanique a été nécessaire à l'unité des soins intensifs. Par la suite, une fistule œesophagienne, un choc septique et une défaillance organique multiple sont survenus et ont entraîné le décès du patient.

Conclusion : Chez un patient qui présente un rupture spontanée de l'œsophage, les considérations anesthésiques doivent veiller à éviter d'aggraver la rupture œsophagienne et permettre la réanimation soutenue d'une condition inflammatoire morbide.

From the Department of Anaesthesiology and Critical Care Medicine and the Department of Surgical Gastroenterology, Sanjay Gandhi Postgraduate Institute of Medical Sciences, Lucknow, India.

Address correspondence to: Dr. Chandra Kant Pandey, Department of Anaesthesiology and Critical Care Medicine, Sanjay Gandhi

Postgraduate Institute of Medical Sciences, Lucknow 226014, India. Phone: 0091-522-440715, ext. 2490; Fax: 0091-522-440017;

E-mail: ckpandey@sgpgi.ac.in Accepted for publication December 7, 2001.

Revision accepted January 18, 2002. 


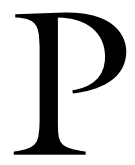

OST-EMETIC spontaneous rupture of the esophagus, also known as Boerhaave's syndrome, is a life threatening condition. The rupture may occur abruptly in a previously healthy patient with an undiseased esophagus. The diagnosis of esophageal rupture can be difficult as the presentation is often non-specific and can be confused with other disorders such as peptic ulceration, pancreatitis, myocardial infarction, dissecting aortic aneurysm, pneumonia, or spontaneous pneumothorax. ${ }^{1,2}$ Prompt diagnosis and early treatment is required to decrease the high mortality of the condition. ${ }^{3}$ Medical literature on the anesthetic management of this condition is scarce. We present the perioperative management of a patient with a spontaneously ruptured esophagus.

\section{Case report}

A 52-yr-old, $60 \mathrm{~kg}$ male with unremarkable previous medical history presented with a seven day history of respiratory distress, chest pain, and swelling in the neck which had developed immediately following forceful vomiting. On admission, examination revealed a respiratory rate of $30 \cdot \mathrm{min}^{-1}$, a pulse rate of $140 \cdot \mathrm{min}^{-1}$ and a blood pressure of $80 / 60 \mathrm{mmHg}$. Tenderness in the epigastrium and abdominal distension with guarding of both right and left hypochondria were present. On auscultation of the chest, air entry in the right lower lung field was markedly decreased and crepitations were audible. Physical examination was otherwise unremarkable. Electrocardiogram, hematology, serum chemistry and coagulation profiles were within normal limits. The chest $x$ - ray revealed a right-sided hydrothorax. The arterial blood gas at a $\mathrm{FIO}_{2}$ of 0.4 revealed a $\mathrm{PaO}_{2}$ of $5 \mathrm{l}$ $\mathrm{mmHg}$, a $\mathrm{PaCO}_{2}$ of $26 \mathrm{mmHg}$, an arterial oxygen saturation of $82 \%, \mathrm{HCO}_{3} 14 \mathrm{mmol} \cdot \mathrm{L}^{-1}$, and a base deficit of $12 \mathrm{mmol} \cdot \mathrm{L}^{-1}$. Esophagogram with contrast medium (sodium diatrizoate) showed extravasation of the contrast material from the lower third of the esophagus into the mediastinum without pleural cavity involvement (Figure). Based on the clinical symptomatology and radiological findings, the diagnosis of rupture of the esophagus was made. Emergency T-tube drainage was planned. Under local anesthesia, a central venous catheter and an arterial cannula were inserted and fluid resuscitation was initiated. Anesthesia was induced with propofol $150 \mathrm{mg}$, fentanyl $150 \mu \mathrm{g}$, vecuronium bromide $6 \mathrm{mg}$, midazolam $3 \mathrm{mg}$ and the patient was intubated with an $8.5-\mathrm{mm}$ cuffed endotracheal tube. Anesthesia was maintained with nitrous oxide and oxygen $(66 \%: 33 \%)$, a continuous infusion of propofol and intermittent boluses of fentanyl and vecuronium bromide. During surgery, fluid administration was guided by central venous pressure, blood loss and urine output.

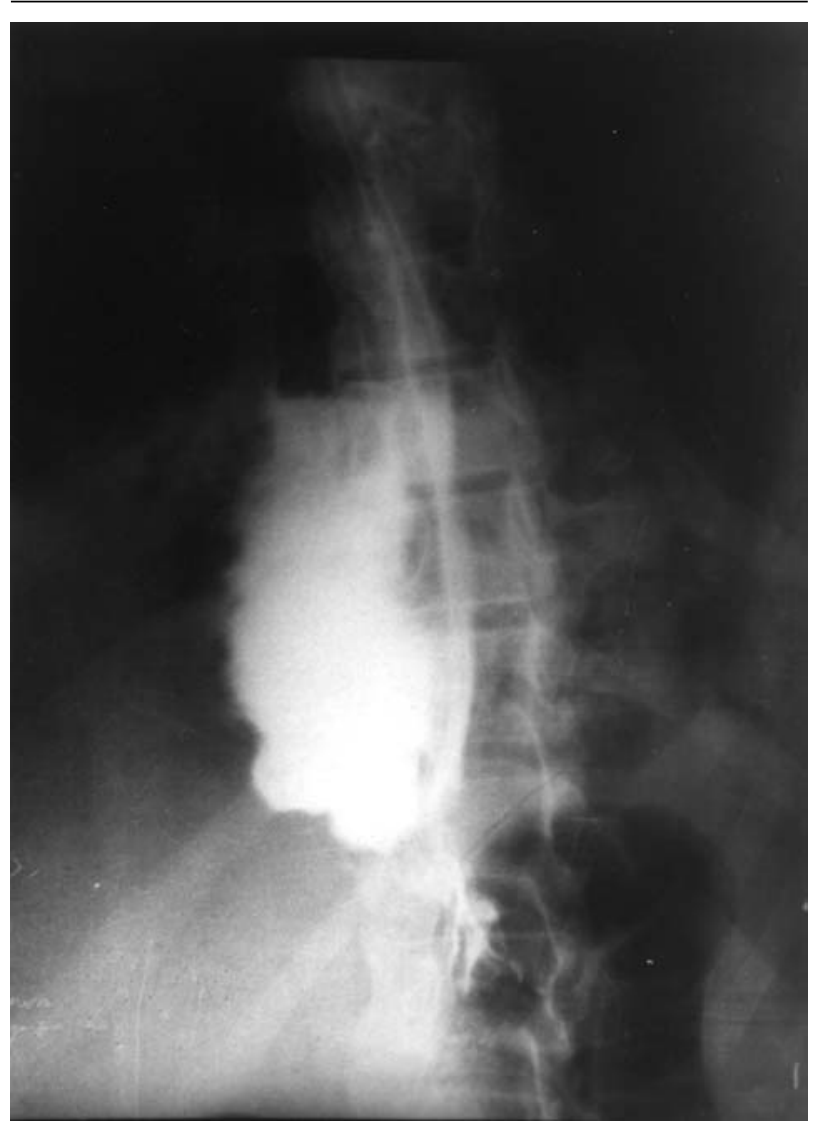

FIGURE Sodium diatrizoate contrast esophagogram demon strating extravasation of contrast material in the mediastinum.

A thoraco-abdominal approach was used for the surgical procedure. On opening the thorax the right lung was congested and inflamed. Necrotic tissue was present in the posterior mediastinum along the course of the middle and lower thirds of the esophagus, along with $2 \mathrm{~L}$ of gastric fluid and undigested food. The right-sided parietal pleura was found to be inflamed and necrotic. A $5-\mathrm{cm}$ transmural tear in the right anterolateral wall of the esophagus, $5 \mathrm{~cm}$ above the gastroesophageal junction, was exposed. The esophageal mucosa was found to be healthy. A reinforced primary surgical closure of the perforated esophagus was performed. A drain was placed in the right pleural cavity. Postoperatively, the patient was moved to the surgical intensive care unit for elective mechanical ventilation. However, his condition deteriorated and he developed septic shock (E Coli were grown from aspirates of mediastinal fluid). Despite appropriate antibiotic, fluid and vasopressor therapy the patient developed multiple organ failure and died on the 1lth day of intensive care 
unit admission. On postmortem examination, approximately $\mathrm{l} \mathrm{L}$ of muddy coloured fluid was present in the right pleural cavity and a leak was found in the repaired segment of the esophagus.

\section{Discussion}

Diagnosis of esophageal rupture is difficult, as the presentation is often non-specific and emulates that of other disorders. ${ }^{1}$ The rupture is usually pressureinduced in origin. This accounts for $30-40 \%$ of all cases of perforations and is the most sinister cause. ${ }^{4}$ It may occur in all age groups, from neonates to elderly individuals, but is most frequent in middle-aged males. ${ }^{5}$ The syndrome usually results from an increase in the intraluminal esophageal pressure, frequently associated with excessive consumption of alcohol and food followed by vomiting. The sudden rise in the intraluminal esophageal pressure tears the distal, left lateral esophageal wall 3 to $5 \mathrm{~cm}$ above the gastroesophageal junction. The tear usually involves the full thickness of the esophagus and communicates with the left pleural cavity in $80 \%$ of cases. ${ }^{6}$ The presenting symptoms are precordial or epigastric pain with a history of prior vomiting or retching. The patient may have tachycardia, diaphoresis, fever and hypotension along with subcutaneous emphysema in the neck. If the leak communicates with the abdomen, signs of peritonitis may be present. ${ }^{6}$ The patient may present with Mackler's classic triad (vomiting, chest pain, and subcutaneous emphysema) or with atypical symptoms. The leak of gastric contents and digestive enzymes into the mediastinum leads to the development of pneumodiastinum and mediastinitis. The mediastinal pleura ruptures because of the inflammatory process, producing pleural effusion. Gastric contents and fluids are drawn into the pleural space by the negative intrathoracic pressure, resulting in further inflammation and fluid sequestration. In turn this results in hypovolemia and appearance of tachycardia and of the systemic inflammatory response syndrome. . $^{1,6}$

Though our patient presented with Mackler's triad, initially the diagnosis was confused with that of pneumonitis. Chest pain, dyspnea, abnormal arterial blood gases, and hydrothorax all suggested the diagnosis of a ruptured esophagus. This was confirmed with a contrast esophagogram and the patient was scheduled for emergency surgery. Because of the patient's delayed reporting to the hospital, T tube drainage was the preoperative surgical plan. However, reinforced primary closure was decided because the mucosa appeared to be healthy. Unfortunately, the anastomosis leaked and resulted in deterioration of the patient's condition and septic shock in the postoperative period.
Medline search did not reveal any literature on anesthetic management of these patients. The anesthetic technique and selection of drugs for the management of esophageal rupture is important. Any manoeuver which increases intra-abdominal pressure increases the risk of gastric contents being pushed out through the esophageal tear and further contaminating the mediastinum. Therefore, induction should be smooth. Coughing and straining should be avoided as they may increase the chances of further tearing in tissue that is already inflamed and friable. Insertion of a nasogastric tube is not recommended as any instrumentation can aggravate the injury to the esophagus. Our patient presented late; however, in cases of early presentation patients are generally considered to have a full stomach since vomiting after a heavy meal is the precipitating factor. Yet the application of Sellick's manoeuver should be avoided to prevent further injury to the esophagus and contamination of the mediastinum. If regurgitation occurs in the presence of cricoid compression, gastric contents will be forced out through the esophageal tear. Because aspiration is a real possibility (full stomach, emergency surgery, no Sellick's manoeuver), induction should be as short as possible. A short acting non-depolarizing muscle relaxant is preferred because depolarizing muscle relaxants (e.g., succinylcholine) are known to raise intra-abdominal pressure. Awake intubation is another possible alternative but it should be attempted cautiously because retching, vigorous coughing or straining during the procedure may aggravate the esophageal tear. In presence of hypoxia and dyspnea, and due to fear of retching, coughing and straining, we did not attempt awake intubation in this patient.

The airway was managed with a cuffed endotracheal tube, but selection of the tube is important. If thoracotomy is performed, it is necessary to place a double lumen endobronchial tube to collapse the ipsilateral lung; however, if a thoraco-abdominal approach is chosen, a single lumen endotracheal tube may suffice. Prior discussion of the surgical technique provides room for modification of the anesthetic plan preoperatively.

Invasive arterial blood pressure monitoring is essential because these patients may present with shock. Also, repeated arterial blood sampling may be required for blood gas analysis perioperatively. A central venous catheter may be helpful for fluid therapy and administration of vasoactive drugs when required. Special attention is required during retrosternal manipulation, because direct pressure on the heart may produce arrhythmias or hypotension. Major blood loss is also expected. Serial hemoglobin and hematocrit measurements can allow accurate assessment of blood loss. 
Appropriate measures should be taken to correct the blood volume by infusion of colloids, crystalloids and blood components. Various factors including prolonged surgery, lung congestion, large fluid shifts, hypothermia, a long surgical incision and pain may lead to postoperative hypoventilation, hypoxia and atelectasis. Elective postoperative mechanical elective ventilation is suggested in these patients.

Our patient did not survive as he presented very late in the course of the disease. Postoperatively, he developed a respiratory distress syndrome, refractory septic shock, and multiple organ failure, probably secondary to a recurring esophageal leak which we were unable to detect.

In summary, we present a patient with a spontaneous rupture of the esophagus. In absence of clear guidelines and based on our experience in this patient, we suggest that anesthetic considerations should include avoidance of aspiration pneumonia and further aggravation of the esophageal tear, and resuscitation from a morbid inflammatory condition.

\section{References}

1 Jones II WG, Ginsberg RJ. Esophageal perforation: a continuing challenge. Ann Thorac Surg 1992; 53: 534-43.

2 Finley RJ, Pearson FG, Weisel RD, Todd TRJ, Ilves R, Cooper $J$. The management of nonmalignant intrathoracic esophageal perforations. Ann Thorac Surg 1980; 30: 575-83.

3 Braner RB, Liebermann-Meffert D, Stein HJ, Bartles $H$, Siewert $J-R$. Boerhaave's syndrome: analysis of the literature and report of 18 new cases. Dis Esophagus 1997; 10: 64-8.

4 Lawrence DR, Ohri SK, Moxon RE, Townsend ER, Fountain $S W$. Primary esophageal repair for Boerhaave's syndrome. Ann Thorac Surg 1999; 67: 818-20.

5 Walker WS, Cameron EWJ, Walbaum PR. Diagnosis and management of spontaneous transmural rupture of the oesophagus (Boerhaave's syndrome). Br J Surg 1985; 72: 204-7.

6 Bjerke HS. Boerhaave's syndrome and barogenic injuries of the esophagus. Chest Surg Clin North Am 1994; 4: 819-25. 